\title{
Three-Dimensional Structures of the Neck Region of the Hamster Spermatozoa in the Caudal Epididymis
}

\author{
Masao Hamasaki, Mitsugu Wakimoto, Toshinori Maehara and Hitoshi Matsuo \\ Department of Anatomy, Kurume University School of Medicine, Kurume, Japan
}

Received September 24, 1993

\begin{abstract}
Summary. Three-dimensional structures of the capitulum and first mitochondria in the neck region of the hamster spermatozoa, were observed with transmission (TEM) and scanning electron microscope (SEM). Some capitula revealed a variable contour even in the caudal epididymis, but most finally developed to form a typical wagonette shape. The final shape of the capitulum is probably produced by the aid of apical protrusion of the right, pyramidal mitochondrium. The right and left first mitochondria were triangular pyramids in contour, while the dorsal and ventral ones were rod-like in shape. The mutual transformations between the capitulum and the first mitochondria are discussed in relation to the completion of the neck region.
\end{abstract}

In the neck region of spermatozoa, the capitulum and the striated column are developed in contact with the centrioles (FAWCETT and PHILLIPS, 1969; ZAMBONI and SteFanini, 1970a, b; WOOLley and FAWCETt, 1973). The capitulum is considered to be composed of a protein, ankyrin, (BACCETTI, 1984; EDDY, 1988), while a fibrous protein comprises the striated column, (FAWCETT and PHILLIPS, 1969, KRETSER and KERR, 1988). The striated column is a common component of mature spermatozoa in all mammalian species. The capitulum, on the other hand, is said to be welldeveloped in rodent sperm, but to be lacking in humans and monkeys (ZAMBONI and STEFANINI, 1970b). For this reason, the function of the capitulum remains unclear. In addition, there is little morphological information concerning the first mitochondria of the neck region. Though the fine structure of the components of the neck region has been precisely observed with regard to the process of spermiogenesis, the final configuration of their components remains obscure. Furthermore, our knowledge on the stereomorphic structures of such completed components has also been restricted even in modern litera- ture dealing with the specific field concerned (BAO et al., 1992). This paper demonstrates the three-dimensional profile of the neck region of almost completed spermatozoa in the caudal portion of the hamster epididymis, with special attention to the capitulum and mitochondria.

\section{MATERIALS AND METHODS}

Mature golden hamsters were intraperitoneally anesthetized with nembutal (10-15 mg/BW), and transfused with physiological saline through the left ventricle and fixed with $2.5 \%$ glutaraldehyde- $2 \%$ paraformaldehyde in $0.1 \mathrm{M}$ cacodylate buffer. The fixed blocks of the caudal epididymis were immersed for $2 \mathrm{~h}$ in the same fixative and were routinely prepared for transmission electron microscopy (TEM). Other blocks were similarly immersed for more than $2 \mathrm{~h}$, demembranated by treatment with $10 \% \mathrm{H}_{2} \mathrm{O}_{2}$ solution for 10 $\mathrm{min}$, to be then processed routinely for scanning electron microscopy (SEM). Except for demembranation of the mature spermatozoa, the protocols for TEM and SEM were followed as in our previous report (HAMASAKI et al., 1983).

\section{RESULTS}

Except for some developing spermatids, a large number of nearly mature spermatozoa appeared in the caudal tubules of epididymis. When cut on a sagittal or coronal plane, they were easily discriminated into three different regions: head, neck and middle piece. In Figure 1 two mature spermatozoa have been cut along right or left coronal plane of the head region, respectively. A magnified TEM profile is shown in Figure 2, in which the neck region of the 


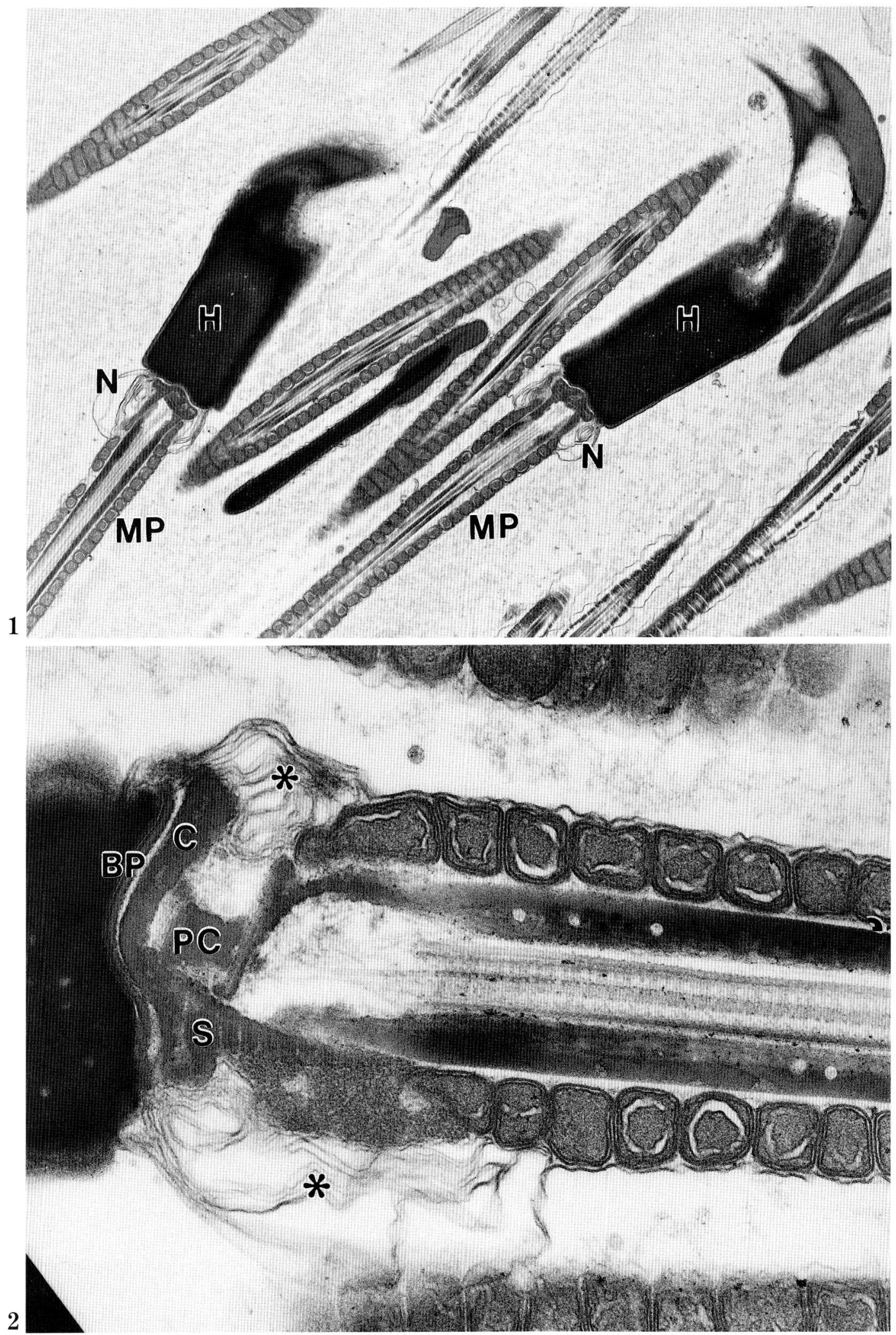

Fig. 1. Two hamster spermatozoa in the caudal epididymal tubule cut along the coronal planes of their head regions $(H)$. The neck region $(N)$ and the middle piece $(M P) . \times 7,300$

Fig. 2. Higher magnification of the neck region of a mature spermatozoon. Basal plate $(B P)$, capitulum $(C)$, proximal centriole $(P C)$, striated column $(S)$ and abundant nuclear membrane $(*) . \times 43,000$ 


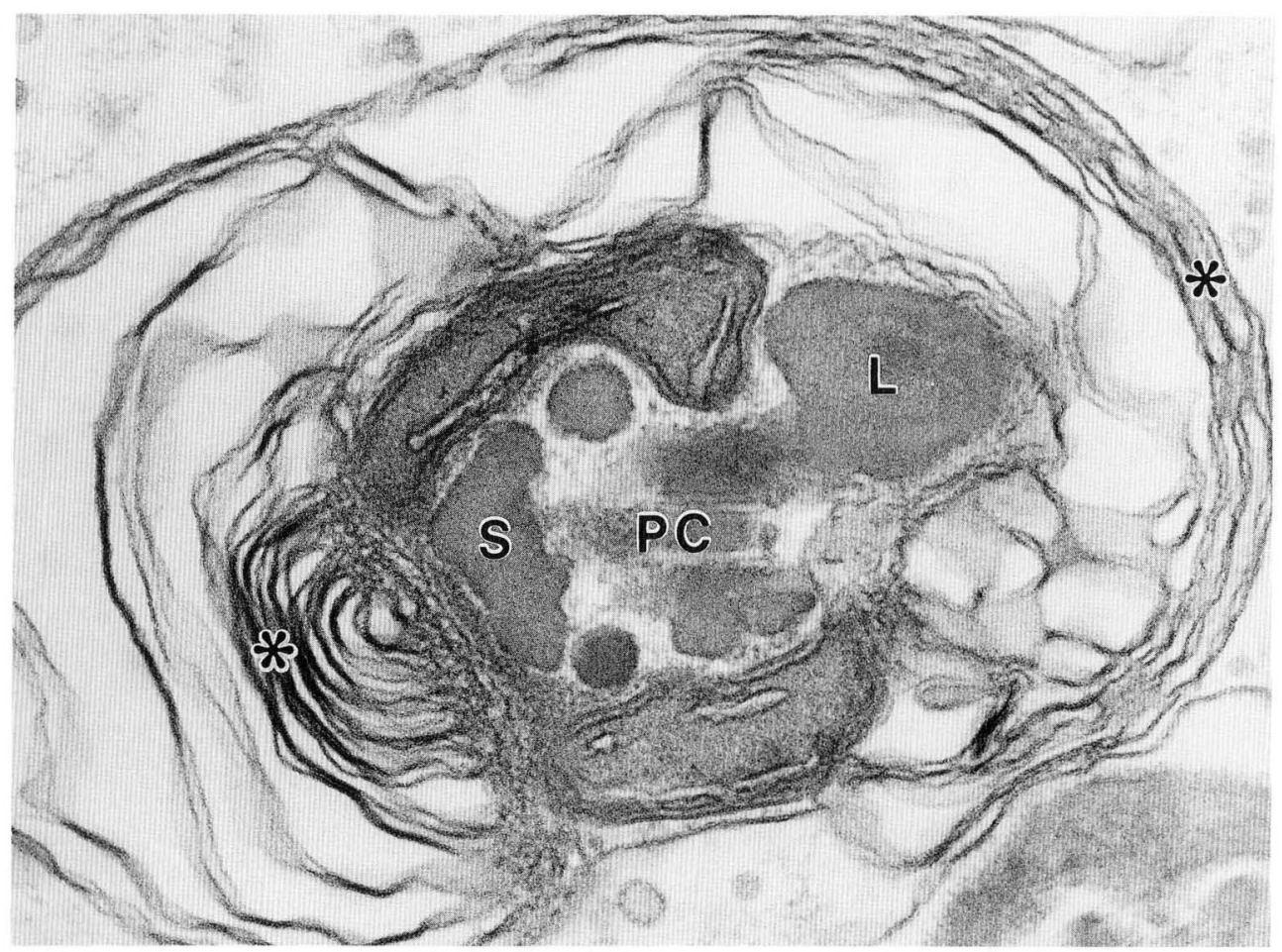

Fig. 3. The horizontal plane of the neck region of a mature spermatozoon. The first rightside mitochondrium protrudes innerward to form a triangular pyramid. Large $(L)$ and small $(S)$ plates of the capitulum; proximal centriole $(P C)$ and abundant nuclear membrane $(*)$. $\times 57,000$

spermatozoa was cut along an axis titled somewhat to the left against the coronal plane. The center of the neck region was composed of the basal plate, the capitulum, the proximal centriole and the space which the distal centriole had occupied inside the striated column, the first mitochondria, and the redundant nuclear envelope. In order to account for their three-dimensional profiles, we must establish the orientation of this region because some of its components often showed different contours due to the direction from which they can be viewed. We therefore considered four directions of the neck region: the right, left, dorsal and ventral faces. The onset of the mitochondrial sheath consisted of four first mitochondria which were located in the right, left, dorsal and ventral faces of the neck portion of the spermatozoa, respectively. Figure 3 shows a horizontal section of the neck portion of a spermatozoon. Some edges of the right mitochondrium protrude inward to push the caudal part of the proximal centriole toward the left side, and further protrude upward to lift the central area of the capitulum to some extent. The right and left mitochondria were seen as triangular pyramids, while the dorsal and ventral ones showed rod-like contours. There were overridings of the first, dorsal and ventral mitochondrial ends (Fig. 4).

When mature spermatozoa were immersed in $10 \%$ $\mathrm{H}_{2} \mathrm{O}_{2}$ solution at room temperature, the cytoplasmic membrane and the abundant nuclear membrane were dissolved either partially or completely. The neck region was separated from the head region and, as a result, it was possible to identify the capitulum with SEM. In the caudal portion of the epididymis, the capitula of mature spermatozoa varied as a discuslike structure (Fig. 5a), a triangular cap (Fig. 5b) or the frame of the wagonette (Fig. $5 \mathrm{c}$ ). This wagonette consisted of the apical projection of the central area, the ventral large disk (major part) and the dorsal small disk (minor part). The ventral disk sloped moderately towards the central area, while the dorsal disk showed an abrupt tilt.

The configuration of most capitula, which resembled the frame of a wagonette, showed a shape complementary to that of the basal plate extending along the dorso-ventral axis of the spermatozoon, closely resembling an articulation (Figs. 5, 6). The articular surface of the capitulum often appeared 


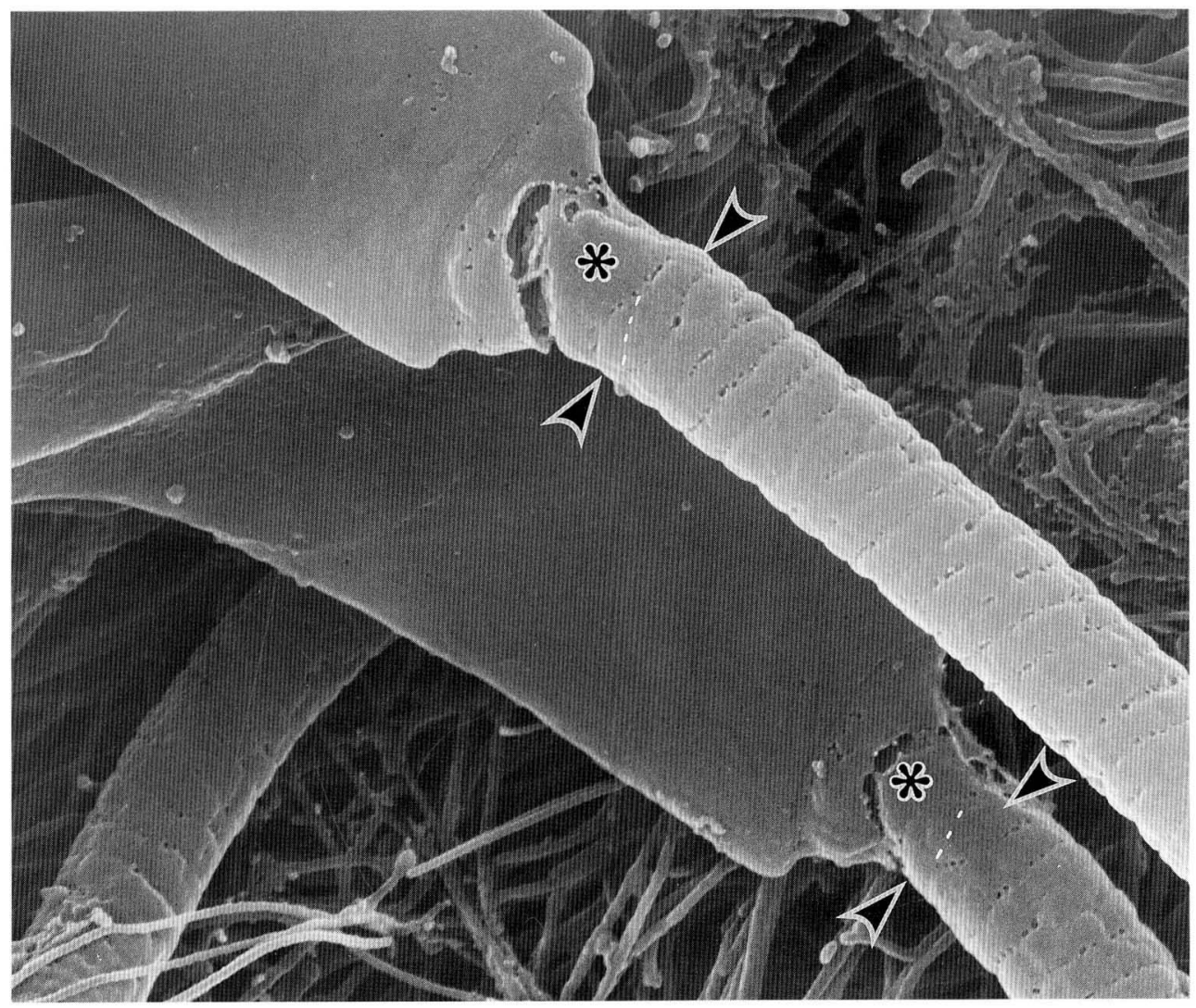

Fig. 4. The first left mitochondrium $(*)$, resembling the first right one, shows a triangular contour, demonstrating a different profile from the first dorsal and ventral ones (arrowheads). The hatched lines indicate overriding of both mitochondrial ends. $\times 32,000$

bent to the right or to the left (Fig. 7), but not at a dorsal or ventral angle to the axis of the basal plate. Fused clots of the dorso-vental striated columns were also recognizable both in SEM (Fig. 7a) and TEM (Fig. 7b).

\section{DISCUSSION}

Previous TEM reports focussed on the development of the neck region of the maturing spermatids during the process of spermiogenesis (FAWCETT and PHILLIPS, 1969; WoOlly and FAWCETt, 1973; ZAMBONI and Stefanini, 1970a, b). The components of the neck region have been intensely studied, but their threedimensional visualization has not completely been achieved.

Recently, methods of chemical-enzymatic dissolution have been applied to expose hidden parts of the cells and tissues and further to clarify their threedimensional structures (EvAN et al., 1976; HAMASAKI et al., 1983). Hydrogen peroxide is used in the field of histochemistry to inhibit endogeneous peroxidase (STRAUS, 1974). If cells are treated with a relatively high concentration of hydrogen peroxide, the cytoplasmic membrane is preferentially dissolved, making underlying structures visible under SEM. The threedimensional visualization of the neck region components of spermatozoa may also be easier and clearer than by any other dissolution methods.

In the caudal portion of the epididymis, the capitula of mature spermatozoa varied as either a discuslike structure, a triangular cap, or the frame of a wagonette. As judged from the extent of the sperm maturation and the frequency distribution, the capitulum is possibly formed in the following order. First, the plate of the capitulum extends from the left to the right edge and appears as a semilunar configuration as a whole. Secondly, the capitulum is transformed into the triangular cap by an apical projection of the first mitochondria. The capitulum then is formed into the final shape such as the frame of a wagonette.

It was first ascertained in the present SEM study that each capitulum changes its three-dimensional 


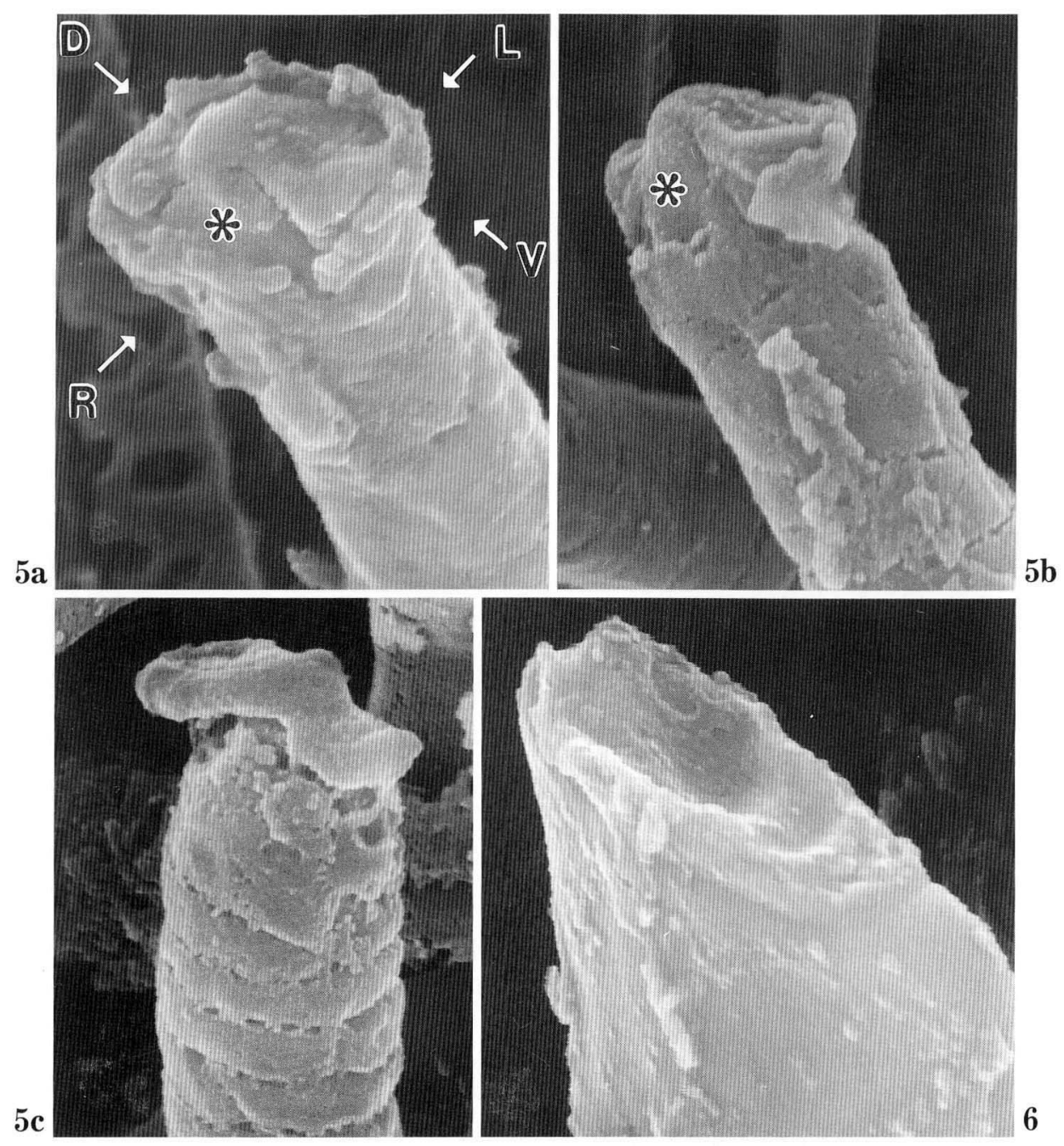

Fig. 5. The neck region of mature spermatozoa, exposed to $10 \% \mathrm{H}_{2} \mathrm{O}_{2}$ solution. The neck regions are shown by SEM from the upper right side (a), the lateral right side (b) and the dorso-lateral left side (c), respectively. The right mitochondrium (*) shows a triangular contour. The arrows indicate right $(R)$, left $(L)$, dorsal $(D)$ and ventral $(V)$ directions. a: $\times 60,000, \mathrm{~b}, \mathrm{c}: \times 61,000$

Fig. 6. SEM image of a basal plate which resembles that of the capitulum. $\times 60,000$

contour during the process of development of the neck region. This variability of the capitulum suggests that the neck region is still in the developing stage even in the caudal portion of the epididymis and that the capitulum may be completed later than any other component of the neck region. On the other hand, one might consider that the differentiation of the capitulum may be incomplete or that even malformed structures may be present. Previous papers reported that the capitulum of the neck region is produced by the proximal centriole during the process of spermiogenesis (FAWCETT and PHILLIPS, 1969; Zamboni and Stefanini, 1970a, b; Woolley and
FAWCETT, 1973). The capitulum has been known to be well developed in the rodents, but to be lacking in the primates (ZAmboni and STEFANini, 1970b). A spiral proceeding movement of the sperm flagellum has been observed in the rodent spermatozoon, but remains unclear in that of primates (SUAREZ et al., 1991). It is thought, therefore, that the existence of the capitulum may be closely related to the spiral proceeding movement of the mature spermatozoon.

The final structure of the neck region is presumed to be decided by a transformation of the first mitochondria as follows. The right and left mitochondria develop their characteristic contours as a triangular 

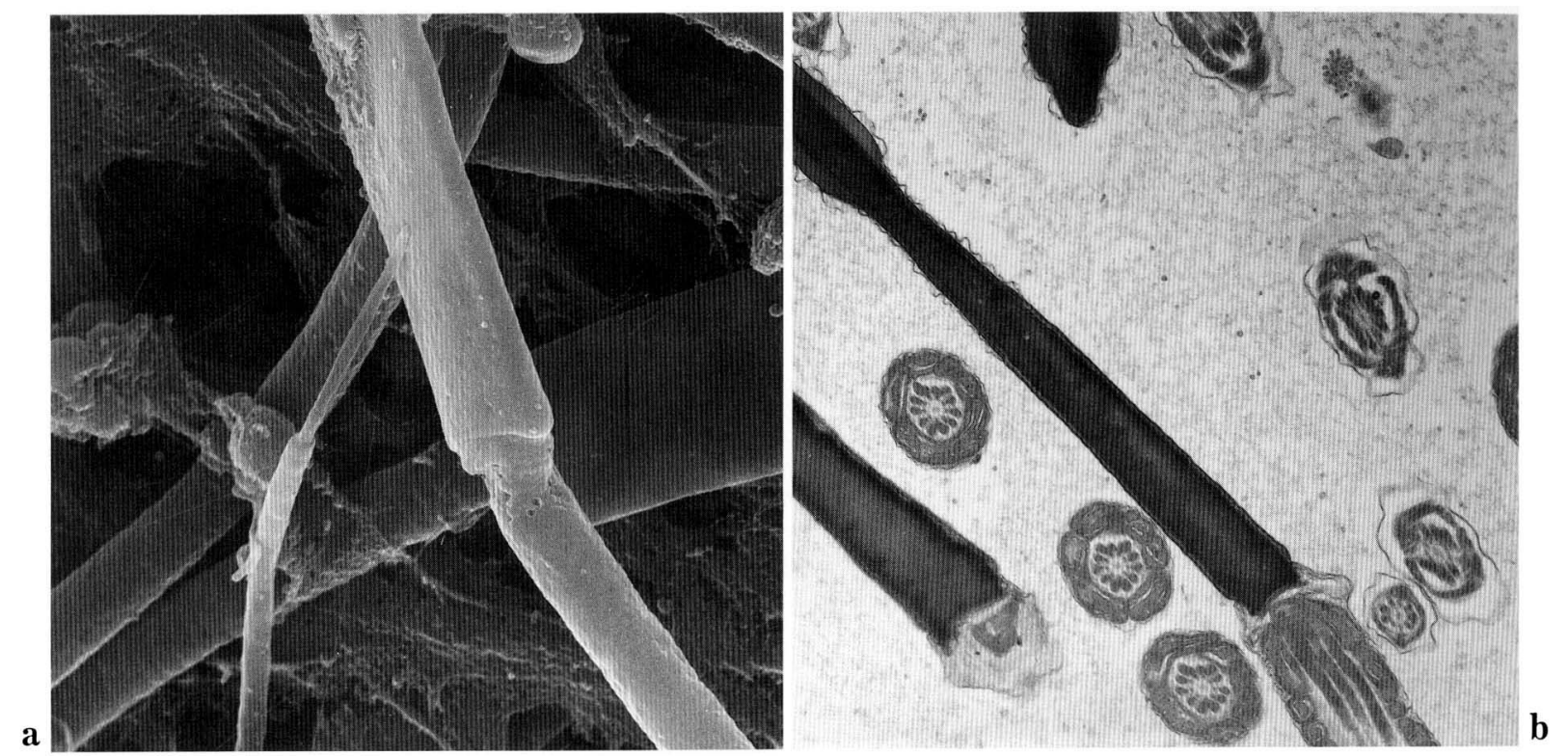

Fig. 7. The head regions of mature spermatozoa bent from the neck regions. Some striated columns are fused to each other in the base of the truncated neck region. a: SEM $\times 18,000$, b: TEM $\times 11,500$

pyramid. The apical tapered edges of both pyramid bodies may cause the central area of the capitulum to be projected upperward and, furthermore, the middle piece of the flagellum changes its shape from a cylinder to a compressed ovoidal cylinder. The inner tapered edge of the right mitochondrium may cause the caudal part of the proximal centriole to be shifted toward the left side to some extent. The first dorsal and ventral mitochondria may shift downward and elongate toward the first right and left mitochondria to form the typical rod-like contour. In the spermatozoon of mosquitoes (BAO et al., 1992), it is reported that the first right and left mitochondria change into granular substances, probably to contribute to form the striated column and further to connect with the outer dense fibers. Although the first dorsal mitochondrium in the hamster is located very close to the granular substances, the real relation between both remains unclear.

Matured sperm in the caudal epididymis is said to move moderately with their flagellum (MOHRI and YANAGIMACHI, 1980; Walt and Hedinger, 1983). The articular facet of the capitulum makes it fit into the mutual mold of the basal plate of the nucleus, but neither structure can function in an arbitrary movement (FAWCETT and PHILliPS, 1969). That the arbitrary movement of the neck bends toward the right and left sides, and not toward the dorsal or ventral side, was ascertained in our study, even though it occurred rather infrequently. The basal body is considered to control the beating apparatus of the motile cilia as in the simple ciliate columnar epithelium of the rat trachea (KRSTIC, 1979) and monkey oviduct (ANDERSON, 1972). In the neck region of complete sperms, the proximal centriole, the capitulum and the striated column may correspond to the basal body in the motile cilia. Though it remains unclear which one may be critical for the beating movement, the above mentioned components are among the candidates for the apparatus. The reasons for this assumption are as follows: 1) Appropriate treatment of some enzymes can easily separate the head region from the neck region of mature sperms. In this case, the motility of these flagella is said to disappear (MOHRI and YANAGIMACHI, 1980). 2) The presence of actin fibers has been demonstrated immunocytochemically in the neck region of spermatozoa in the hamster (FLAHERTY et al., 1988). 3) The actin fibers, which coil up to the doublets of the axonema, are also recognized in the connecting centriole of the photoreceptor cell (OBATA and USUKURA, 1992). It is generally accepted at present that the dynein arms of the peripheral doublets of the axonema play a major role in effecting the flagellar movement (SUGRUE et al., 1991). Nevertheless, it is possible that the neck region might play a minor role in controlling the tilt toward the right or left side during the rotating and proceeding movement of mature sperm. This point remains to be clarified. 


\section{REFERENCES}

Anderson, R. G. W.: The three-dimensional structure of the basal body from the rehesus monkey oviduct. J. Cell Biol. 54: 246-265 (1972).

BACCETTI, B.: The human spermatozoon. In: (ed. by) J. V. BLERKOM and P. M. MOTTA: Ultrastructure of reproduction: gametogenesis, fertilization, and embryogenesis. Martinus Nijhoff, The Hague, 1984 (p. 110-126).

Bao, S. N., U. Lins, M. Farina and W. Souza: Mitochondrial derivatives of Culex quinque-fasciatus (Culicidae) spermatozoon; Some new aspects evidenced by cytochemistry and image processing. J. Str. Biol. 109: 46-51 (1992).

EDDY, E. M.: The spermatozoon In: (ed. by) E. KNoBIL and J. D. NeILL: The physiology of reproduction. Raven Press, New York, 1988 (Vol. 1, p. 27-68).

Evan, A. P., W. G. Dail, D. Dammrose and C. Palmer: Scanning electron microscopy of cell surfaces following removal of extracellular material. Anat. Rec. 185: 433446 (1976).

FawcetT, D. W. and D. M. PhiliIPs: The fine structure and development of the neck region of the mammalian spermatozoon. Anat. Rec. 165: 153-184 (1969).

Flaherty, S. P., W. P. Winfrey and G. E. Olson: Localization of actin in human, bull, rabbit and hamster sperm by immunoelectron microscopy. Anat. Rec. 221: 599-610 (1988).

Hamasaki, M., T. InoKUChI and M. Murakami: Stereomorphic structure of the intercellular bridges between rat seminiferous epithelial cells. J. Electron Microsc. 32: 141-151 (1983).

Kretser, E. M. D. and J. B. KerR: The cytology of the testis. In: (ed. by) E. KNOBIL and J. D. NeILL: The physiology of reproduction. Raven Press, New York, 1988 (Vol. 1, p. 837-932)

KRSTIC, R. V.: Ultrastructure of the mammalian cell. Springer-Verlag, Berlin-Heidelberg, 1979.

Mohri, H. and R, Yanagimachi: Characteristics of moter apparatus in testicular, epididymal and ejaculated spermatozoa. Exp. Cell Res. 127: 191-196 (1980).
Obata, S. and J. UsukuRa: Morphogenesis of the photoreceptor outer segment during postnatal development in the mouse (BALB/C) retina. Cell Tiss. Res. 269: 39-48 (1992).

STRAUs, W.: Cleavage of heme from horse-radish peroxidase by methanol with inhibition of enzymatic activity. J. Histochem. Cytochem. 22: 908-915 (1974).

SuARez, S. S., D. F. Katz, D. H. OWEn, J. B. ANDReW and R. L. Powell: Evidence for the function of hyperactivated motility in sperm. Biol. Reprod. 44: 375-381 (1991).

Sugrue, P., J. Avolio., P. Satir and M. E. J. Holwill: Computer modelling of Tetrahymena axonema at macromolecular resolution. Interpretation of electron micrographs. J. Cell Sci. 98: 5-16 (1991).

W Alt, H. and C. Hedinger: Motile components in spermatids as related to transport of spermatids and spermatozoa. Andrologia 15(1): 34-39 (1983).

Woolley, D. M. and D. W. FAwCETT: The degeneration and disappearance of the centrioles during the development of the rat spermatozoon. Anat. Rec. 177: 289-302 (1973).

Zamboni, L. and M. Stefanini: The fine structure of monkey and human spermatozoa. Anat. Rec. 169: 129$154(1970 \mathrm{a})$

- : The fine structure of the neck of mammalian spermatozoa. Anat. Rec. 169: 155-172 (1970b).

Dr. Masao HAMASAKI

Department of Anatomy

Kurume University School of Medicine

Asahimachi, Kurume

Fukuoka, 830 Japan

浜 崎 正 雄

830 福岡県久留米市旭町 67

久留米大学医学部

第二解剖学教室 